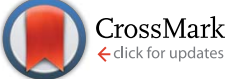

Cite this: RSC Adv., 2016, 6, 81847

Received 15th June 2016 Accepted 19th August 2016

DOI: 10.1039/c6ra15519g

www.rsc.org/advances

\section{New one-pot method for the synthesis of pyrrolidinofullerenes $\uparrow$}

\author{
A. R. Tuktarov, ${ }^{\text {a }}{ }^{\text {Z. R. Shakirova, }}{ }^{\text {a }}$ Yu. G. Budnikova, ${ }^{\text {b }}$ R. B. Salikhov ${ }^{c}$ \\ and U. M. Dzhemilev ${ }^{a}$
}

\begin{abstract}
The reaction of fullerene $\mathrm{C}_{60}$ with isocyanoacetates and $\mathrm{EtMgBr}$ in the presence of stoichiometric amounts of $\mathrm{Ti}(\mathrm{Oi}-\mathrm{Pr})_{4}$ was studied for the first time. Unlike esters and nitriles of carboxylic acids and isonitriles, isocyanoacetates were found to react with $\mathrm{C}_{60}$ under the developed conditions to give $\mathrm{N}$-unsubstituted pyrrolidinofullerenes. The electrochemical reduction of the $\mathrm{C}_{60}$ derivatives we synthesized was found to proceed less easily than that of $\mathrm{C}_{60}$ but more easily than that of unsubstituted pyrrolidinofullerenes.
\end{abstract}

\section{Introduction}

The interest in pyrrolidinofullerenes is caused by their potential applications in medicine, ${ }^{\mathbf{1}}$ in electronics and non-linear optics ${ }^{2}$ and as organic ferromagnets, ${ }^{3}$ photosensitizers in the generation of singlet oxygen, ${ }^{4}$ molecular switches, ${ }^{5}$ and photoconverters of solar energy. ${ }^{6}$

The key method for the synthesis of pyrrolidinofullerenes is 1,3-dipolar cycloaddition of azomethine ylides generated in situ to fullerenes (Prato reaction), which gives the target fulleroheterocycles in preparative yields. ${ }^{7}$ Alternative methods

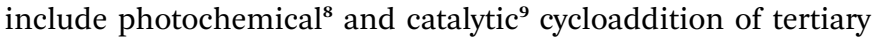
amines to $\mathrm{C}_{60}$, but these methods have not received wide use in fullerene chemistry because of low yields of the target adducts or the necessity to use starting amines of a particular structure.

Recently, ${ }^{\mathbf{1 0}}$ we developed a novel original method for functionalization of fullerene $\mathrm{C}_{60}$ with various functional compounds and EtMgBr in the presence of $\mathrm{Ti}(\mathrm{Oi}-\mathrm{Pr})_{4}$, which gave, depending on the reactant structure, various acyclic or cyclic $\mathrm{C}_{60}$ derivatives difficult to prepare by other methods. For example, esters of aromatic carboxylic acids give fullerenyl ketones in this reaction, ${ }^{\mathbf{1 0 a}}$ nitriles afford previously unknown

${ }^{a}$ Institute of Petrochemistry and Catalysis, Russian Academy of Sciences, Russian Federation.E-mail: tuktarovar@gmail.com

${ }^{b}$ Arbuzov Institute of Organic and Physical Chemistry, Kazan Research Center, Russian Academy of Sciences, Russian Federation

${ }^{c}$ Bashkir State University, Russian Federation

† Electronic supplementary information (ESI) available. See DOI: 10.1039/c6ra15519g fullerotetrahydropyridines, ${ }^{\mathbf{1 0 b}}$ and cyanoacrylates and isonitriles are converted to aminomethanofullerenes previously difficult to obtain. ${ }^{10 c, \boldsymbol{d}}$

As a continuation of this study, we investigated the reaction of $\mathrm{C}_{60}$ with isocyanoacetates under the previously developed conditions. ${ }^{\mathbf{1 0}}$

\section{Result and discussion}

Resorting to published data, ${ }^{\mathbf{1 0}-12}$ we assumed that isocyanoacetates containing divalent carbon in the carbene canonical form and an active methylene group between the isonitrile and ester groups would react with fullerene $\mathrm{C}_{60}$ and EtMgBr in the presence of the $\mathrm{Ti}(\mathrm{Oi}-\mathrm{Pr})_{4}$ catalyst to give pyrrolidinofullerenes, which are difficult to obtain by other methods, according to the following chart:

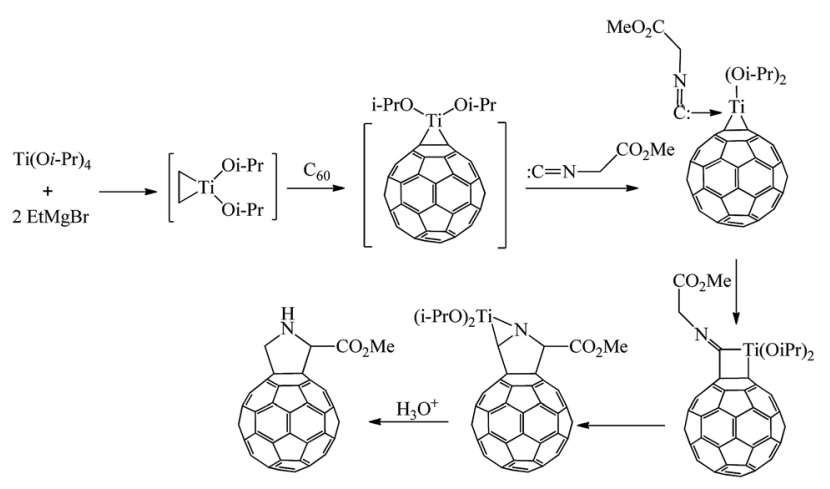

We found that the reaction of model methyl isocyanoacetate with fullerene $\mathrm{C}_{60}$ and $\mathrm{EtMgBr}$ proceeds under argon in the presence of $\mathrm{Ti}(\mathrm{Oi}-\mathrm{Pr})_{4}$ in chlorobenzene at $80{ }^{\circ} \mathrm{C}$ at the $\mathrm{C}_{60}$ : isocyanoacetate : $[\mathrm{Mg}]:[\mathrm{Ti}]$ ratio of $1: 4: 8: 3$ and gives, after hydrolysis of the reaction mixture with $5 \%$ aqueous $\mathrm{HCl}$, a mixture of pyrrolidinofullerene stereoisomers $\mathbf{1 a}$ and $\mathbf{1 b}$ in $\mathrm{a} \sim 65 \%$ total yield (in relation to taken $\mathrm{C}_{60}$ ) and in $1: 2$ ratio, respectively (Scheme 1). A change in the ratio of the reactant and catalyst components and a decrease in the reaction 


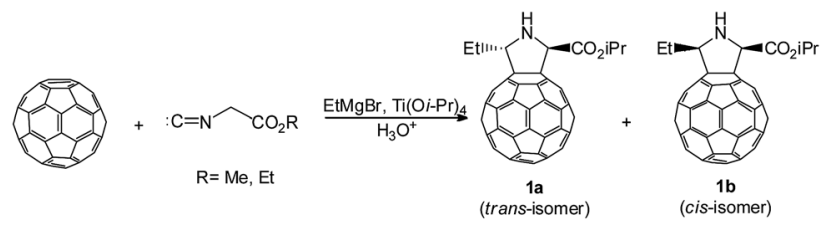

Scheme 1 The reaction of methyl or ethyl isocyanoacetates with fullerene $\mathrm{C}_{60}$ and $\mathrm{EtMgBr}$ in the presence of $\mathrm{Ti}(\mathrm{Oi}-\mathrm{Pr})_{4}$.

temperature result in a sharp decrease of the total yield of target pyrrolidinofullerenes $\mathbf{1 a}, \mathbf{b}(8-15 \%)$ and in the formation of side products via $\mathrm{C}_{60}$ carbomagnesiation and hydrogenation.

The results obtained using ethyl isocyanoacetate rather than methyl isocyanoacetate were similar.

Pyrrolidinofullerenes 1a,b were isolated from the reaction mixture by means of preparative HPLC. According to $1 \mathrm{D}\left({ }^{1} \mathrm{H}\right.$ and ${ }^{13} \mathrm{C}$ ) and 2D (HHCOSY, HSQC, HMBC) NMR experiments and IR and MALDI TOF MS data, the reaction under conditions we developed affords a mixture of stereoisomeric cycloadducts $\mathbf{a}$ and $\mathbf{b}$.

Indeed, the ${ }^{13} \mathrm{C}$ NMR spectrum of a mixture of stereoisomers 1a,b shows a doubled set of signals with $1: 2$ intensity ratio both for carbon atoms of the fullerene cage and for the attached addend. The intense signals at $\delta_{\mathrm{C}} 79.38$ and $78.34 \mathrm{ppm}$ correspond to the $\mathrm{sp}^{3}$ hybridized atoms of the fullerene cage of cisisomer $\mathbf{1 b}$, while the methine carbon atoms of the pyrrolidine ring are responsible for higher-field signals at $\delta_{\mathrm{C}} 74.20$ and $75.24 \mathrm{ppm}$, correlated with the nitrogen signal in the HMBC $(\mathrm{NH})$ experiment, $\delta_{\mathrm{N}} 60.96 \mathrm{ppm}$. For trans-isomer 1a, the spectrum exhibits a set of similar signals of low intensity, belonging to the $\mathrm{sp}^{3}$ hybridized carbon atoms of $\mathrm{C}_{60}\left(\delta_{\mathrm{C}} 76.77\right.$ and 77.58 ppm), methine carbon atoms of the heterocycle $\left(\delta_{\mathrm{C}} 72.32\right.$ and $74.03 \mathrm{ppm})$, and the nitrogen atom $\left(\delta_{\mathrm{N}} 55.17 \mathrm{ppm}\right)$. The $C\left(3^{\prime}\right)$ methine carbon signals of $c i s-\left(\delta_{\mathrm{C}} 75.24 \mathrm{ppm}\right)$ and trans- $\left(\delta_{\mathrm{C}} 74.03\right.$ ppm) isomers also show cross-peaks with the signals of the ethyl-group methylene protons $\left(\delta_{\mathrm{H}} 2.20\right.$ and $2.32 \mathrm{ppm}$, respectively) in the HMBC spectra. The cis-configuration of the $1^{\prime}, 3^{\prime}$ substituents in $\mathbf{1 b}$ was unambiguously proved by the crosspeaks in the NOESY experiment between the methine proton signals at $\delta_{\mathrm{H}}\left(1^{\prime}\right) 5.43 \mathrm{ppm}$ and $\delta_{\mathrm{H}}\left(3^{\prime}\right) 4.68 \mathrm{ppm}$, whereas transisomer 1a does not show this cross-peak.

The formation of stereoisomeric pyrrolidine cycloadducts 1a,b of the composition $\mathrm{C}_{68} \mathrm{H}_{15} \mathrm{NO}_{2}$ was confirmed by the MALDI TOF mass spectrometry. The experiments were performed in the linear (TOF) and reflection (TOF/TOF) modes and in both positive and negative ion modes using elemental sulfur as the matrix and showed the molecular ion $[\mathrm{M}+\mathrm{H}]$ peak, $\mathrm{m} / \mathrm{z}$ 878.044 $\left(M_{\text {calcd }}=877.110\right)$.

According to the published ${ }^{\mathbf{1 1 , 1 2}}$ and our $^{\mathbf{1 0}}$ experimental data, we assumed a probable pathway for the formation of pyrrolidinofullerene $\mathbf{1}$ in the reaction in question (Scheme 2). In the first step, $\mathrm{Ti}(\mathrm{Oi}-\mathrm{Pr})_{4}$ reacts with $\mathrm{EtMgBr}$ to give dialkoxytitanocyclopropane occurring in equilibrium with the ethylene complex. Fullerene present in the reaction mixture displaces the ethylene molecule from the complex to afford the key reaction intermediate, namely, fullerotitanacyclopropane $\mathbf{A}$.

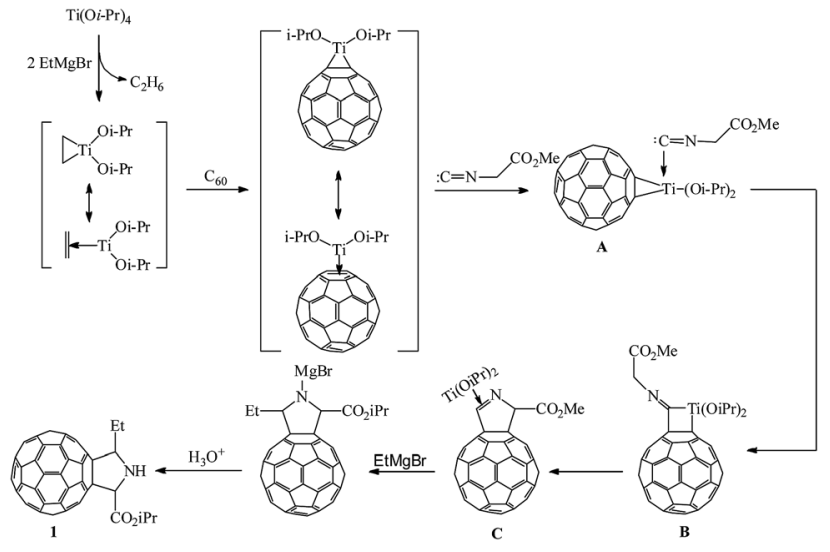

Scheme 2 Probable pathway for the formation of pyrrolidinofullerenes in the reaction of isocyanoacetates with fullerene $\mathrm{C}_{60}$ and $\mathrm{EtMgBr}$ in the presence of $\mathrm{Ti}(\mathrm{Oi}-\mathrm{Pr})_{4}$.

The subsequent reaction of intermediate $\mathbf{A}$ with the isocyanoacetate at the metal-carbon bond yields titanacyclobutane B. Demetallation of $\mathbf{B}$ under the reaction conditions and subsequent transformations involving the reactive methylene group of the starting isonitrile result in the formation of pyrrolinofullerene $\mathbf{C}$. In view of the excess of EtMgBr and Ti(Oi-Pr $)_{4}$ in the reaction mixture, the intermediate $\mathbf{C}$ undergoes carbomagnesiation of the heterocyclic moiety at the $\mathrm{C}=\mathrm{N}$ bond with simultaneous transesterification of the ester group, being thus converted to complex $\mathbf{D}$, which is hydrolyzed to furnish the target pyrrolidinofullerene $\mathbf{1}$.

In view of the fact that the structure of substituents in the pyrrolidine ring of the $\mathrm{C}_{60}$ derivative depends on the structure of the $\mathrm{Mg}$ organic compound, we carried out this reaction under the developed conditions using a variety of alkyl- and arylmagnesium bromides (Scheme 3, Table 1). More bulky structure of substituent in the initial organomagnesium compound was found to lead to higher proportions of trans-fulleropyrrolidines, up to the selective formation of the trans-isomers in the case of $\mathrm{PhMgBr}$. The introduction of a substituent into the aromatic ring of the organomagnesium compound reduced the selectivity, and the reaction gave a mixture of stereoisomeric pyrrolidinofullerenes 6 with a cis to trans ratio of $1: 2$, indicating that the electronic effects as well as the steric effects influence on selectivity of formation of the cis,trans isomers.

As model compounds, we chose phenyl-substituted fulleropyrrolidine $\mathbf{5}$ and study the electrochemical reduction.

Fulleropyrrolidine 5 can reversibly add four electrons in four steps (Fig. 1) to give stable multianions:

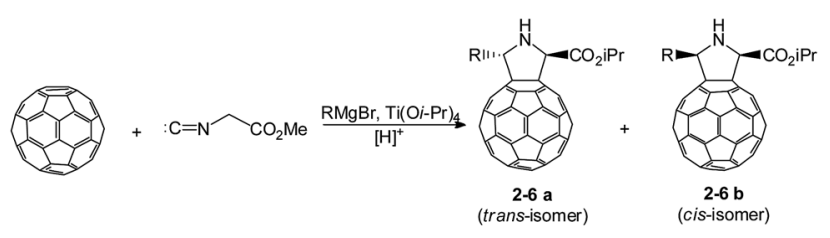

Scheme 3 Variation of alkyl- and arylmagnesium bromides in the reaction of $\mathrm{C}_{60}$ with methyl isocyanoacetate. 
Table 1 Effect of the structure of substituent in RMgX on the selectivity of formation of pyrrolidinofullerenes 2-6

\begin{tabular}{llllll}
\hline & & & & \multicolumn{2}{c}{ Ratio } \\
\cline { 5 - 6 } Entry & $\mathrm{R}$ & Product & Yield, \% & $a$ & $b$ \\
\hline 1 & $\mathrm{Bu}$ & 2 & 50 & 2 & 3 \\
2 & $\mathrm{i}-\mathrm{Pr}$ & 3 & 55 & 1 & 1 \\
3 & $\mathrm{Cy}$ & 4 & 51 & 8 & 10 \\
4 & $\mathrm{Ph}$ & 5 & 45 & 1 & 0 \\
5 & $o-\mathrm{MePh}$ & 6 & 43 & 2 & 1 \\
\hline
\end{tabular}

$$
\mathrm{F} 5+\mathrm{e} \stackrel{\mathrm{E}_{1}}{\rightleftharpoons} \mathrm{F} 5^{-}+\mathrm{e} \stackrel{\mathrm{E}_{2}}{\rightleftharpoons} \mathrm{F}^{2-}+\mathrm{e} \stackrel{\mathrm{E}_{3}}{\rightleftharpoons} \mathrm{F}^{3-}+\mathrm{e} \stackrel{\mathrm{E}_{4}}{\rightleftharpoons} \mathrm{F}^{4-}
$$
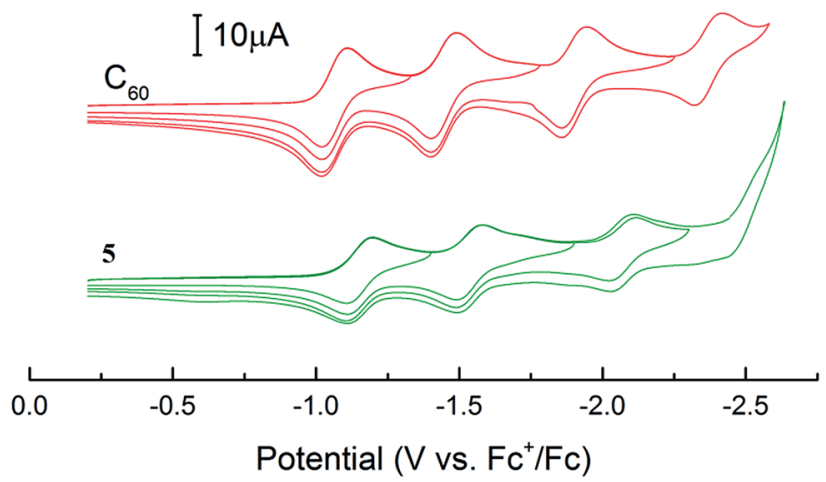

Fig. 1 Cyclic voltammograms of $C_{60}$ and its novel derivative $5\left(10^{-3} \mathrm{M}\right.$ in 1,2-dichlorobenene, $\mathrm{Bu}_{4} \mathrm{NBF}_{4}$ ).

The first reduction potentials of functionally substituted fullerene $\mathbf{5}$ are somewhat more negative than that of fullerene $\mathrm{C}_{60}$, which is caused by the effect of substituents (Table 2). The fourth reduction peak is is nearly merged with the background. The stability of the electrochemically reduced fullerene species (radical anion formed in the first step and polyanions formed in the subsequent steps) can be evaluated from the ratio of anodic and cathodic currents in the $i_{\mathrm{pa}} / i_{\mathrm{pc}}$ peak (Table 2).

Table 2 Electrochemical characteristics of the reduction of compound

\begin{tabular}{llllllll}
\hline Comp. & Peak \# & $E_{\mathrm{pc}}$ & $E_{\mathrm{pa}}$ & $i_{\mathrm{pa}} / i_{\mathrm{pc}}$ & $\Delta E$ & $E_{1 / 2}$ & $E_{\mathrm{LUMO}}$ \\
\hline $\mathbf{5}$ & 1 & -1.20 & -1.11 & 0.73 & 0.09 & -1.16 & -3.65 \\
& 2 & -1.58 & -1.49 & 1.00 & 0.09 & -1.54 & -3.27 \\
& 3 & -2.12 & -2.02 & 1.00 & 0.10 & -2.07 & -2.73 \\
& 4 & -2.54 & $\mathrm{~N} / \mathrm{A}$ & $\mathrm{N} / \mathrm{A}$ & $\mathrm{N} / \mathrm{A}$ & $\mathrm{N} / \mathrm{A}$ & $\mathrm{N} / \mathrm{A}$ \\
$\mathrm{C}_{60}{ }^{a}$ & 1 & -1.11 & -1.02 & 0.95 & 0.09 & -1.07 & -3.74 \\
& 2 & -1.49 & -1.40 & 1.00 & 0.09 & -1.45 & -3.36 \\
& 3 & -1.95 & -1.86 & 1.00 & 0.09 & -1.91 & -2.9 \\
& 4 & -2.42 & -2.32 & 0.76 & 0.1 & -1.37 & -2.43
\end{tabular}

${ }^{a}$ The data for $\mathrm{C}_{60}$ are close to reported values. ${ }^{13}$ obtained under similar conditions. Due to proximity of the fourth peak to the supporting electrolyte discharge line, the calculation of $i_{\mathrm{pa}} / i_{\mathrm{pc}}$ is in some cases not appropriate (this is designated as N/A). The LUMO energy (eV) was calculated as $E_{\mathrm{LUMO}}=-\left(E_{\left[1 / 2, \mathrm{red} v \text { s. } \mathrm{Fc}^{+} / \mathrm{Fc}\right]}+4.8\right)(\mathrm{eV}) .^{14}$
It is known that the effect of substituents present in the $\mathrm{C}_{60}$ molecule on the reduction potentials is composed of two effects, namely, the change in the electronic properties of the proper fullerene sphere as a result of disruption of the common $\pi$-system of conjugation and the electron-donating or -withdrawing properties of the substituents. For example, the substituents at the exo-carbon atom of $\mathrm{C}_{60}$ in methanofullerene 2 are not involved in the common fullerene $\pi$-system, which can be regarded as the reaction center of the electron transfer by two $\sigma$-bonds; therefore, they affect only slightly the reduction potentials of $\mathrm{C}_{60}$ derivatives. The potential shift reported in the literature for this class of carbon clusters is in the limits of up to $200 \mathrm{mV} .{ }^{15}$ Meanwhile, strong electron-withdrawing substituents in methano ${ }^{-16}$ or azahomofullerenes ${ }^{17}$ can overcompensate for the loss of electron affinity as a result of disruption of $\pi$-system of conjugation. The cyclopentane and cyclohexane derivatives of $\mathrm{C}_{60}$ are 100 and $80 \mathrm{mV}$ more difficult to reduce than parent $\mathrm{C}_{60}{ }^{18}$ while the presence of a nitrogen atom in fulleropyrrolidines has a slight influence on the potentials of the first two reduction steps compared with cyclopentane derivatives. ${ }^{19}$

The electrochemical reduction of fulleropyrrolidine $\mathbf{5}$ was found to occur at more negative potentials than that of the parent $\mathrm{C}_{60}$ (the difference is $60-90 \mathrm{mV}$ ). This distinguish compound 5 from unsubstituted pyrrolidinofullerene. This results indicate that the introduction of an aryl substituent and ester group into the heterocyclic fragment of $\mathbf{5}$ compensates, to a certain extent although not completely, for the loss of the electron affinity caused by disruption of the $\pi$-system of conjugation.

Unfortunately, we were unable to correctly calculate the $E_{\mathrm{HOMO}}$ and thus to determine the band gap width of the acceptor $\left(E_{\mathrm{g}}\right)$ on the basis of cyclic voltammetry data because the

Table 3 Conductivity of 5 and $\mathrm{C}_{60}$ at $60^{\circ} \mathrm{C}$

\begin{tabular}{lll}
\hline Compound & $G, \mathrm{ohm}^{-1}\left(\right.$ at $\left.60^{\circ} \mathrm{C}\right)$ & $\Delta E, \mathrm{eV}$ \\
\hline 5 & $1.5 \times 10^{-11}$ & 1.54 \\
$\mathrm{C}_{60}$ & $1.4 \times 10^{-11}$ & 1.63
\end{tabular}

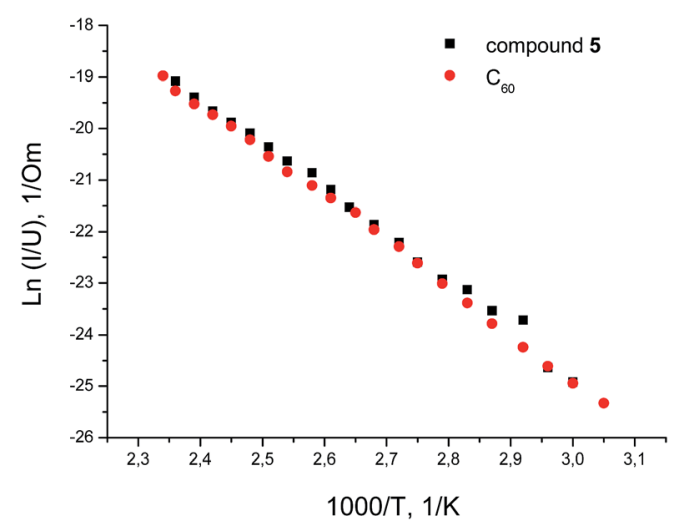

Fig. 2 Temperature dependence of the conductivity of films of 5 and $\mathrm{C}_{60}$. 
oxidation waves of compound $\mathbf{5}$ are multielectron, which may be caused by sample polymerization under conditions of electrochemical measurements.

Nevertheless, the band gap width can be determined by electrophysical methods, in particularly, from the plot of the dependence of the film conductivity $G$ on temperature $T$ in the range of 300-450 K. These dependences are exponential, $G=$ $G_{0} \exp (-\Delta E / 2 k T)$. From the slope of the linear segments, it was possible to calculate $\Delta E$ for each sample; the result was about 1.5-1.6 eV. Meanwhile, the $\Delta E$ value can be interpreted as $E_{\mathrm{g}}$ (the gap between the LUMO and the HOMO).

It is found that the conductivity of 5 differs little from unmodified fullerene (Table 3), but is characterized by better solubility in organic solvents (Fig. 2).

\section{Conclusions}

Thus, we developed a new method for the synthesis of $\mathrm{N}$ unsubstituted pyrrolidinofullerenes by the $\mathrm{Ti}(\mathrm{Oi}-\mathrm{Pr})_{4}$-catalyzed reaction of $\mathrm{C}_{60}$ with isocyanoacetates and EtMgBr. The electrochemical reduction of model pyrrolidinofullerene occurs less easily than that of $\mathrm{C}_{60}$ but more easily than that of unsubstituted pyrrolidinofullerenes, which may imply that introduction of new substituents into the heterocyclic fragment compensates somewhat for the loss of electron affinity of the fullerene cage.

\section{Acknowledgements}

This work was supported by the Russian Foundation for Basic Research (Grant No. 15-03-01042), the Russian Science Foundation (Grant No. 14-13-00296) and Ministry of Education and Science of the Russian Federation (Sci.Sc.-6651.2016.3). The structural studies of fullerene derivatives were performed with use of Collective Usage Centre "Agidel" at Institute of Petrochemistry and Catalysis of RAS and "Spectro-Analytical Center" at the Institute of Organic and Physical Chemistry AE Arbuzov of RAS.

\section{Notes and references}

1 (a) R. Fong, D. I. Schuster and S. R. Wilson, Org. Lett., 1999, 1, 729; (b) T. Da Ros and M. Prato, Chem. Commun., 1999, 663; (c) A. Hirsch and M. Brettreich, Fullerenes, Wiley-VCH, Weinheim, 2005, p. 426.

2 T. Yamashiro, Y. Aso, T. Otsubo, H. Tang, Y. Harima and K. Yamashita, Chem. Lett., 1999, 28, 443.

3 (a) D. G. Zheng, Y. L. Li, Z. Mao and B. Zhu, Synth. Commun., 1998, 28, 879; (b) Y.-L. Li, Z. Mao, J.-H. Xu, Y.-K. Yang, Z.-X. Guo, D.-B. Zhu, J.-W. Li and B. Yin, Chem. Phys. Lett., 1997, 361; (c) Y.-L. Li, J.-H. Xu, D.-G. Zheng, J. K. Yang, C.-Y. Pan and D.-B. Zhu, Solid State Commun., 1997, 101, 123. 4 B. Ma, C. E. Bunker, R. Guduru, X. F. Zhang and Y. P. Sun, J. Phys. Chem. A, 1997, 101, 5626.

5 (a) A. R. Tuktarov, A. A. Khuzin, L. M. Khalilov, A. R. Tulyabaev, A. R. Akhmetov and U. M. Dzhemilev, Mendeleev Commun., 2015, 25, 470; (b) S. Castellanos,
A. A. Vieira, B. M. Illescas, V. Sacchetti, C. Schubert, J. Moreno, D. M. Guldi, S. Hecht and N. Martin, Angew. Chem., Int. Ed., 2013, 52, 13985; (c) A. R. Tuktarov, A. A. Khuzin, A. R. Akhmetov, V. A. Barachevsky, O. V. Venidiktova and U. M. Dzhemilev, Tetrahedron Lett., 2015, 56, 7154; (d) P. A. Liddell, G. Kodis, A. L. Moore, T. A. Moore and D. Gust, J. Am. Chem. Soc., 2002, 124, 7668; (e) J.-H. Xu, Y.-L. Li and D.-B. Zhu, Synth. Commun., 2002, 32, 1647; (f) J. Frey, G. Kodis, S. D. Straight, T. A. Moore, A. L. Moore and D. Gust, J. Phys. Chem. A, 2013, 117, 607; (g) J. Zhang, K. Porfyrakis, J. J. L. Morton, M. R. Sambrook, J. Harmer, L. Xiao, A. Ardavan and G. A. D. Briggs, J. Phys. Chem. C, 2008, 112, 2802.

6 (a) H. Imahori, H. Yamada, Y. Nishimura, I. Yamazaki and Y. Sakata, J. Phys. Chem. B, 2000, 104, 2099; (b) H. Imahori and Y. Sakata, Eur. J. Org. Chem., 1999, 10, 2445; (c) P. A. Troshin, R. N. Lyubovskaya and V. F. Razumov, Nanotechnol. Russ., 2008, 3, 242; (d) D. Mi, H.-U. Kim, J.-H. Kim, F. Xu, S.-H. Jin and D.-H. Hwang, Synth. Met., 2012, 162, 483.

7 M. Maggini, G. Scorrano and M. Prato, J. Am. Chem. Soc., 1993, 115, 9798.

8 (a) G. E. Lawson, A. Kitaygorodskiy, B. Ma, C. E. Bunker and Y.-P. Sun, Chem. Commun., 1995, 2225; (b) K.-F. Liou and C.-H. Cheng, Chem. Commun., 1996, 1423; (c) S.-H. Wu, D.-W. Zhang, G.-W. Wang, L.-H. Shu, H.-M. Wu, J.-F. Xu and X.-F. Lao, Synth. Commun., 1997, 27, 2289; (d) S.-H. Wu, G.-W. Wang, L.-H. Shu, H.-M. Wu, S.-K. Jiang and J.-F. Xu, Synth. Commun., 1997, 27, 1415; (e) G. E. Lawson, A. Kitaygorodskiy and Y.-P. Sun, J. Org. Chem., 1999, 64, 5913; (f) L.-W. Gao, X. Gao, D.-W. Zhang, S.-H. Wu, H.-M. Wu and Y.-J. Li, J. Org. Chem., 2000, 65, 3804. 9 (a) U. M. Dzhemilev, A. G. Ibragimov, M. Pudas, V. A. D'yakonov and A. R. Tuktarov, Russ. J. Org. Chem., 2007, 43, 370; (b) O. A. Troshina, P. A. Troshin, A. S. Peregudov and R. N. Lyubovskaya, Mendeleev Commun., 2007, 17, 113; (c) S. Filippone, E. E. Maroto, A. Martín-Domenech, M. Suarez and N. Martín, Nat. Chem., 2009, 1, 578; (d) U. M. Dzhemilev and A. R. Tuktarov, Metal complex catalysis in the chemistry of fullerenes, in: Handbook on Fullerene: Synthesis, properties and applications, ed. R. F. Verner and C. Benvegnu, Nova Science Publishers, Inc., ISBN 978-1-62100-429-5, 2012, pp. 241-312.

10 (a) U. M. Dzhemilev, M. A. Famutdinova, N. R. Popod'ko and A. R. Tuktarov, Tetrahedron Lett., 2013, 54, 3260; (b) A. R. Tuktarov, A. A. Khuzin, Z. R. Shakirova and U. M. Dzhemilev, Tetrahedron Lett., 2014, 55, 5003; (c) A. R. Tuktarov, Z. R. Shakirova, A. A. Khuzin, A. R. Tulyabaev, I. R. Ramazanov and U. M. Dzhemilev, Synthesis, 2016, 48, 136; (d) A. R. Tuktarov, Z. R. Shakirova, A. A. Khuzin, A. R. Tulyabaev, I. R. Ramazanov and U. M. Dzhemilev, Tetrahedron Lett., 2016, 40, DOI: 10.1016/ j.tetlet.2016.08.044.

11 Y. Tsunenishi, H. Ishida, K. Itoh and M. Ohno, Synlett, 2000, 9, 1318. 
12 D. Liu, S. Yang and S.-T. Lee, J. Phys. Chem. C, 2008, 112, 7110.

13 T. Wakahara, Y. Maeda, M. Kako, T. Akasaka, K. Kobayashi and S. Nagase, J. Organomet. Chem., 2003, 685, 177.

14 C. M. Cardona, W. Li, A. E. Kaifer, D. Stockdale and G. C. Bazan, Adv. Mater., 2011, 23, 2367.

$15 \mathrm{~V}$. V. Yanilkin, Elektrokhimiya Fullerenov (Fullerene Electrochemistry), A chapter of the collective monograph Elektrokhimiya Organicheskikh Soedinenii v Nachale XXI Veka (Electrochemistry of Organic Compounds at the Beginning of the 21st Century), ed. V. P. Gultyai, A. G. Krivenko and A. P. Tomilov, Sputnik, Moscow, 2008, pp. 178-249.

16 K. M. Keshavarz, B. Knight, R. C. Haddon and F. Wudl, Tetrahedron, 1996, 52, 5149.
17 O. G. Sinyashin, I. P. Romanova, G. G. Yusupova, A. A. Nafikova, V. I. Kovalenko, N. M. Azancheev, V. V. Yanilkin and Y. G. Budnikova, Mendeleev Commun., 2000, 10, 61.

18 T. Suzuki, Y. Maruyama, T. Akasaka, W. Ando, K. Kobayashi and S. Nagase, J. Am. Chem. Soc., 1994, 116, 1359.

19 (a) V. P. Gubskaya, E. V. Ovechkina, V. V. Yanilkin, V. I. Morozov, N. V. Nastapova, V. V. Zverev, N. M. Azancheev and I. A. Nuretdinov, Russ. Chem. Bull., 2005, 54, 334; (b) I. A. Nuretdinov, V. V. Yanilkin, V. I. Morozov, V. P. Gubskaya, V. V. Zverev, N. V. Nastapova and G. M. Fazleeva, Russ. Chem. Bull., 2002, 51, 263. 